Article

\title{
Evaluation of Moist Static Energy in a Simulated Tropical Cyclone
}

\author{
Lijun $\mathrm{Yu}^{1}$, Shuhui $\mathrm{Wu}^{2}$ and Zhanhong Ma ${ }^{1, *}$ \\ 1 College of Meteorology and Oceanography, National University of Defense Technology, \\ Nanjing 211101, China; lijunyu198208@163.com \\ 2 Department of Finance, Sanjiang University, Nanjing 211101, China; shuhuiwu0205@163.com \\ * Correspondence: hongzhanm@163.com
}

Received: 21 May 2019; Accepted: 5 June 2019; Published: 12 June 2019

\begin{abstract}
The characteristics of moist static energy (MSE) and its budget in a simulated tropical cyclone (TC) are examined in this study. Results demonstrate that MSE in a TC system is enhanced as the storm strengthens, primarily because of two mechanisms: upward transfer of surface heat fluxes and subsequent warming of the upper troposphere. An inspection of the interchangeable approximation between MSE and equivalent potential temperature $\left(\theta_{e}\right)$ suggests that although MSE is capable of capturing overall structures of $\theta_{e}$, some important features will still be distorted, specifically the low-MSE pool outside the eyewall. In this low-MSE region, from the budget analysis, the discharge of MSE in the boundary layer may even surpass the recharge of MSE from the ocean. Unlike the volume-averaged MSE, the mass-weighted MSE in a fixed volume following the TC shows no apparent increase as the TC intensifies, because the atmosphere becomes continually thinner accompanying the warming of the storm. By calculating a mass-weighted volume MSE budget, the TC system is found to export MSE throughout its lifetime, since the radial outflow overwhelms the radial inflow. Moreover, the more intensified the TC is, the more export of MSE there tends to be. The input of MSE by surface heat fluxes is roughly balanced by the combined effects of radiation and lateral export, wherein a great majority of the imported MSE is reduced by radiation, while the export of MSE from the TC system to the environment accounts for only a small portion.
\end{abstract}

Keywords: tropical cyclone; moist static energy

\section{Introduction}

Variations of tropical cyclone (TC) intensity and structure are closely related to the energetic characteristics [1,2]. Warm ocean water provides the energy source for a TC, and through upward fluxes of sensible heat and latent heat, the TC increases in internal energy (IE) and latent energy (LE). By converting the energy supplied by the ocean into kinetic energy (KE) via moist convection, the wind strengthens and consequently the TC intensifies [2,3].

Moist static energy (MSE) comprises IE, LE, and potential energy (PE), and is thus indicative of the total energy acquired from the ocean. As constructed, MSE has an approximate conservation property under hydrostatic and adiabatic motion, even in the presence of phase changes between the liquid and vapor phases of water (the Appendix demonstrates its limitations). Therefore, it is a commonly used term for diagnosing various weather systems. Emanuel [4] identified that the concept of MSE is functional in deducing the theory of maximum potential intensity. Wong and Emanuel [5] proposed that the intensity of a mature TC should be proportional to the difference between the MSE of the eyewall and the undisturbed environment. Their finding offers potential for estimating TC intensity using radiometers. From the energy perspective, a TC cannot develop without eyewall updrafts transporting MSE upward from the boundary layer. By employing a simplified TC model in 
which the saturation MSE is set as a threshold value for deep convection, Zhu and Smith [6] found that both shallow convection and precipitation-induced downdrafts had an effect of lowering the boundary-layer MSE, which is a sign of the energy exchange between the boundary layer and the lower troposphere.

Rather than directly measuring the behavior of MSE, it is more often replaced by an approximately equivalent term, equivalent potential temperature $\left(\theta_{e}\right)$, when examining the thermodynamics of convection systems [7-12]. Although this study illustrates that this interchangeable approximation has limitations, the characteristics of $\theta_{e}$ do have implications for understanding MSE. By conducting a series of air-sea coupling simulations, Bender and Ginis [7] suggested that the cold wake evidently hinders the intensification of a TC by undermining MSE (represented by $\theta_{e}$ ). Fierro et al. [10,11] examined MSE (represented by $\theta_{e}$ ) in tropical convection systems and demonstrated that buoyant tropical oceanic clouds transport high-MSE air in the boundary layer upward, into the upper troposphere. During this process, a small portion of the high MSE is diluted and consequently MSE in the midtroposphere is enhanced. Many observations have evidenced that rainband-induced downdrafts of low $\theta_{e}$ (MSE) air could enter the boundary layer [13-17]. Such low-energy air, when vertical shear of the environmental wind is present, can invade into the core region and "anti-fuel" the TC engine, which would be detrimental to TC intensification [18].

The MSE budget, given its assumed conservation of energy, is a convenient framework for evaluating energy recharge-discharge mechanisms during various weather events, for instance, the Madden-Julian oscillation [19-22]. In TCs, investigations on the MSE budget are very limited. Frank [23] composited 10 years of rawinsonde data to calculate the budgets of MSE, angular momentum, and KE. However, due to insufficient surface data, their main findings of MSE budget were constrained to an estimation of the values of sea surface heat fluxes and the surface exchange coefficient. McBride (1981) conducted a volume budget of MSE using rawinsonde data from both the Atlantic and Pacific basins. Those calculations of energy balance demonstrated that TCs are maintained only through energy received from the ocean, and that for both pre-hurricane and hurricane cloud clusters, the systems export MSE by transverse circulation, as also stated by Yanai et al. [24]. However, these two studies are constrained by poor resolution of observation data and a lack of surface enthalpy fluxes, which preclude further digging.

Recently, cloud-resolving models can be performed at very high spatial and temporal resolutions (e.g., Chen et al. [25]), therefore dynamically consistent data with detailed three-dimensional TC information can be reproduced. Using high-resolution model output, this study aims to systematically examine the characteristics and budget of MSE in TCs. While the $\theta_{e}$ structures in TCs have been extensively observed or simulated, this study will also show that the distributions of MSE are not identical to those of $\theta_{e}$ and that the interchangeable approximation between these two terms can be problematic. The next section introduces the model configurations, equations for MSE budget, and an overview of the simulated TC. Section 3 investigates the spatial distributions of MSE. Section 4 mainly diagnoses the column MSE budget in the boundary layer and upper outflow layer. Section 5 discusses the volume budget of MSE. Section 5 concludes with a summary of the results.

\section{Model Setup, MSE Formulation, and Overview of the Simulated Storm}

\subsection{Model Setup}

We used the same model configuration as Ma et al. [26], which is introduced here for completeness. This study uses the Weather Research and Forecasting (WRF) model version 3.2 [27]. The model is set on an $f$ plane at $20^{\circ} \mathrm{N}$, containing three domains with horizontal resolution of 15,5 , and $1.67 \mathrm{~km}$ and dimensions of $220 \times 220,202 \times 202$, and $301 \times 301$. The nested domains move automatically to follow the storm center. The cumulus processes are represented explicitly and no parameterization scheme has been used. The Lin scheme [28] is used to model the microphysical processes. The Yonsei University (YSU) scheme [29] is chosen as the planetary boundary layer scheme. The Dudhia shortwave [30] 
and rapid radiative transfer model (RRTM) longwave [31] schemes are used as the radiation schemes. Thirty-one levels were placed as default in the vertical direction, with the model top set at $50 \mathrm{hPa}$.

The quiescent and horizontally uniform environmental fields are specified at all levels according to the mean tropical sounding of temperature and humidity profiles given by Jordan [32]. The underlying model boundary is set uniformly to be sea surface with a constant temperature of $28^{\circ} \mathrm{C}$ and a surface pressure of $1010 \mathrm{hPa}$. A bogus vortex in hydrostatic and gradient wind balance is implanted in the idealized atmosphere environment with a maximum wind speed of $24 \mathrm{~m} \mathrm{~s}^{-1}$ at a radius of $125 \mathrm{~km}$. The model is integrated for a total of $144 \mathrm{~h}$, with the model output at intervals of $30 \mathrm{~min}$.

\subsection{MSE Formulation}

MSE is defined as

$$
h=c_{p} T+g z+L_{v} q,
$$

where $h$ is MSE, $c_{p}$ is the specific heat at constant pressure, $T$ is temperature, $g$ is gravitational acceleration, $z$ is height, $L_{v}$ is the latent heat of vaporization, and $q$ is the specific humidity. The three terms on the right-hand side represent IE, PE, and LE, respectively. The MSE budget in $z$ and cylindrical coordinates translating with the storm is given by:

$$
\frac{d h}{d t}=\frac{\partial h}{\partial t}+u \frac{\partial h}{\partial r}+\frac{v}{r} \frac{\partial h}{\partial \lambda}+w \frac{\partial h}{\partial z}=S_{1}-S_{2}
$$

where $t, r$, and $\lambda$ denote time, radius, and azimuth; and $u, v$, and $w$ denote radial, tangential and vertical winds. $S_{1}$ is the energy source and $S_{2}$ is the energy sink. Decomposing the basic quantities into azimuthal mean and perturbation components, and averaging Equation (2) along the azimuthal direction, then multiplying the equation with air density $(\rho)$ and integrating it from the sea surface to the top of the model atmosphere $\left(H_{T}\right)$, a vertical integral form of the MSE budget similar to Maloney (2009) can be obtained:

$$
\left.\left\langle\frac{\partial \bar{h}}{\partial t}\right\rangle+\left\langle\bar{u} \frac{\overline{\partial h}}{\partial r}\right\rangle+\left\langle\bar{w} \frac{\overline{\partial h}}{\partial z}\right\rangle+\overline{\left\langle u^{\prime} \frac{\partial h^{\prime}}{\partial r}\right.}+\overline{\frac{v^{\prime}}{r} \frac{\partial h^{\prime}}{\partial \lambda}}+\overline{w^{\prime} \frac{\partial h^{\prime}}{\partial z}}\right\rangle=(L H+S H)-\langle L W+S W\rangle
$$

where the four terms on the left-hand side represent azimuthal mean local MSE tendency (TEN), mean horizontal advection (HADV), mean vertical advection (VADV), and eddy processes (EDDY). The two terms on the right-hand side represent surface sensible and latent heat fluxes, and integrated radiation heating rate due to long wave and short wave, respectively. The sum of TEN, HADV, VADV, and EDDY equals the net MSE acquired by column atmosphere, denoted as DTH. Here, $<x>$ denotes the mass-weighted vertical integral of quantity $x$ :

$$
<x>=\int_{z=0}^{z=H_{T}} \rho x d z .
$$

The primary difference in the MSE budget between this study and Frank [23] is that the asymmetric effects (EDDY) are considered in Equation (3). Unlike in Frank [23], where the radiation cooling rate was estimated from previous observational profiles, in WRF the radiation schemes provide long-wave fluxes at the ground surface (GLW) and the top of the atmosphere (OLR), but the corresponding short-wave fluxes are not calculated. Following Maloney [19], the short-wave flux is omitted in Equation (3) considering that its contribution is negligible [21]. Analogous to Equation (3), the vertical integrals of MSE over the inflow layer and outflow layer of a storm can be derived:

$$
T E N_{\text {inflow }}+H A D V_{\text {inflow }}+V A D V_{\text {inflow }}+E D D Y_{\text {inflow }}=(L H+S H)-G L W+D T X
$$


and

$$
T E N_{\text {out flow }}+H A D V_{\text {outflow }}+V A D V_{\text {outflow }}+E D D Y_{\text {outflow }}=D B X-O L R,
$$

where DTX and DBX are derived as residuals from Equations (5) and (6), representing the fluxes at the top and bottom of the outflow layer, respectively.

\subsection{Overview of Storm Evolution}

The basic characteristics of the simulated storm, in terms of intensity evolution and wind structures, have been depicted in Ma et al. [26]. They are re-introduced in this subsection for completeness, though these are not the focus of this study. The storm remains stationary throughout the simulation due to the lack of background flow on an $f$ plane (not shown). Figure 1 shows the storm intensity in terms of maximum surface azimuthal mean wind speed (at the lowest model level, about $30 \mathrm{~m}$ altitude) and minimum sea level pressure. In the first $24 \mathrm{~h}$, the storm intensifies rapidly, with its maximum surface wind speed attaining $51 \mathrm{~m} \mathrm{~s}^{-1}$ and minimum sea surface pressure deepening to $954 \mathrm{hPa}$. During this time, the moist processes, low-level inflow, and upper-level outflow are established. This is followed by a slow intensification until about $96 \mathrm{~h}$, when the storm reaches its mature state.

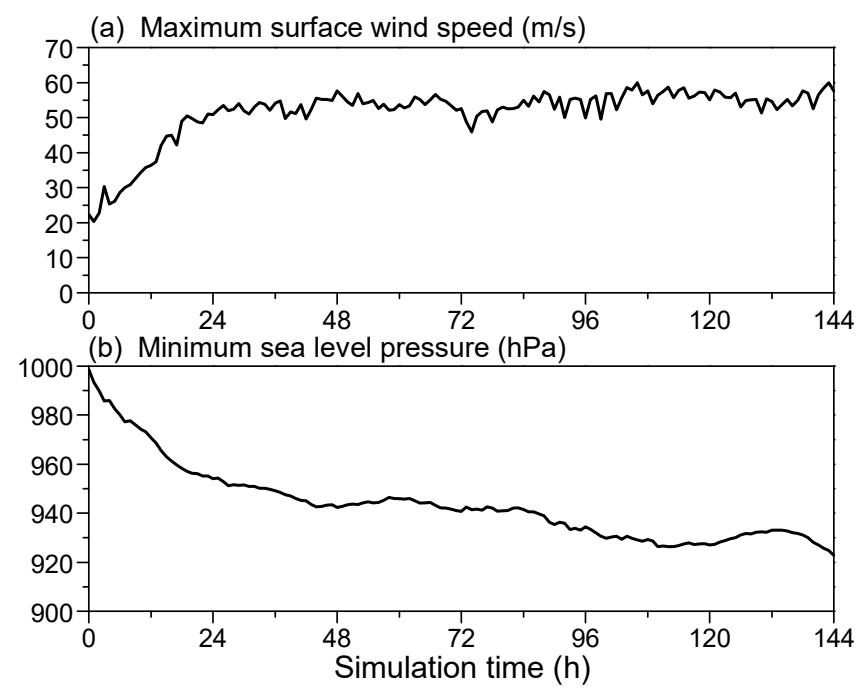

Figure 1. Time evolution of (a) minimum sea level pressure ( $\mathrm{hPa}$ ) and (b) maximum azimuthal mean wind speed at lowest model level $\left(\mathrm{m} \mathrm{s}^{-1}\right)$. The figure incorporates the same information as Figure 1a in Ma et al. (2015) [26].

The azimuthally-averaged tangential winds, radial winds, vertical motion, and potential temperature anomalies exhibit typical features as those of real TCs (Figure 2). The maximum tangential wind exceeds $70 \mathrm{~m} \mathrm{~s}^{-1}$ at a radius of about $40 \mathrm{~km}$. The strongest inflow velocity of about $20 \mathrm{~m} \mathrm{~s}^{-1}$ occurs at about $50 \mathrm{~km}$. The inflow layer is surmounted immediately by a low-level outflow jet, which helps to maintain the local maximum in tangential winds [33]. The outflow of the TC peaks at about $14 \mathrm{~km}$ altitude between 100 and $200 \mathrm{~km}$ radially. It favors the strengthening of warm core by protecting it from environmental ventilation [34]. The ascending flow in the eyewall tilts outward with height, which is more pronounced in the upper troposphere (Figure 2c). The potential temperature anomalies exhibit evident warm-core structure (Figure 2d). There are two maxima in the warm-core center, located at the middle and upper troposphere. 
(a) Tangential winds

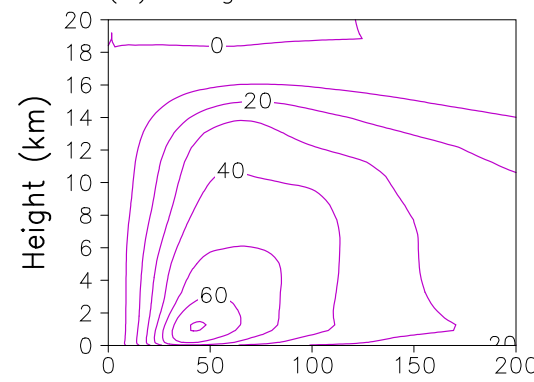

(c) Vertical winds

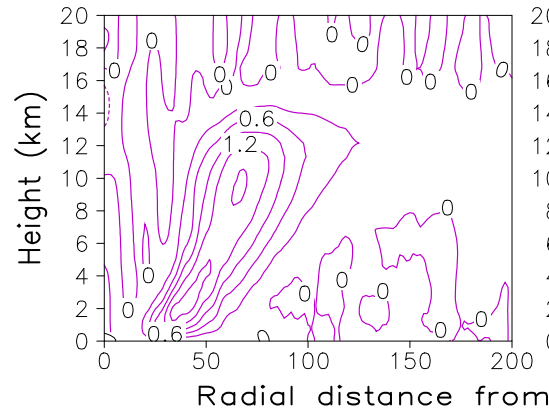

(b) Radial winds

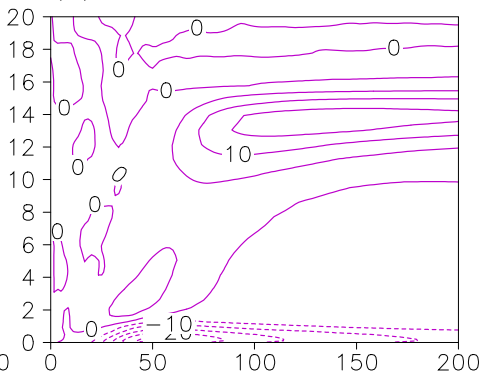

(d) Warm core

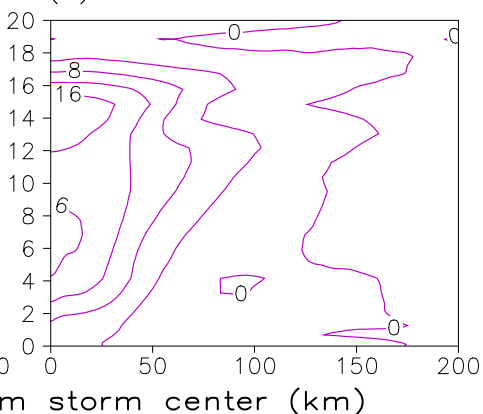

Figure 2. Height-radius cross-sections of azimuthal mean (a) tangential winds $\left(\mathrm{m} \mathrm{s}^{-1}\right)$, (b) radial winds $\left(\mathrm{m} \mathrm{s}^{-1}\right),(\mathbf{c})$ vertical winds $\left(\mathrm{m} \mathrm{s}^{-1}\right)$, and $(\mathbf{d})$ potential temperature anomalies $(\mathrm{K})$ averaged between 108 and $120 \mathrm{~h}$. The panels $(\mathbf{a}-\mathbf{c})$ incorporate the information in Figure $1 \mathrm{~b}$ of Ma et al. (2015) [26], but are vertically extended to $20 \mathrm{~km}$ since an integration from model bottom to model top ( $20 \mathrm{~km}$ ) is used in the following budget analysis.

\section{MSE Structures}

As discussed above, $\theta_{e}$ is used in many studies as an alternative to MSE. Conventionally, there are two forms of $\theta_{e}$, one based on the definition of Bolton [35], hereafter denoted as $\theta_{e 1}$, and the other based on the definition of Rotunno and Emanuel [36], hereafter denoted as $\theta_{e 2}$. In deriving the interchangeable relationship between MSE and $\theta_{e}$, some approximation is applied (see Appendix A). To examine whether the assumption of equivalence between MSE and $\theta_{e}$ is validated in simulations, a comparison of the distributions of MSE, $\theta_{e 1}$, and $\theta_{e 2}$ averaged between 108 and $120 \mathrm{~h}$ is given in Figures 3 and 4 . Note that MSE is normalized by the specific heat at constant pressure $\left(c_{p}\right)$ and is thus in Kelvin, referred to as "equivalent geopotential temperature" by Darkow [37]. As seen in Figure 3, the symmetric structures of MSE are similar to those of $\theta_{e 1}$ and $\theta_{e 2}$. In the low-level inflow layer, MSE and $\theta_{e}$ increase inward rapidly in the eyewall region (Figure 2), an indication of the inflow air continually acquiring energy from the underlying ocean. This leads to a local maximum in the low-level storm center. In the upper troposphere (above approximately $14 \mathrm{~km}$ ), all terms increase upward and have large values relative to other regions. Either $\theta_{e 1}$ or $\theta_{e 2}$ appears to be a good alternative to represent the primary characteristics of MSE. Nonetheless, there are still some differences between these terms. A notable feature is that the vertical gradient of MSE in the upper troposphere is much smaller than that of $\theta_{e 1}$ and $\theta_{e 2}$. The specific values in $\theta_{e 1}$ and $\theta_{e 2}$ are larger than those in MSE over the whole region. This could be because the kinetic energy generation term has been neglected in MSE [26]. There is also a large difference between $\theta_{e 1}$ and $\theta_{e 2}$, more pronounced at low levels (Figure 3d). The difference increases to as large as $6 \mathrm{~K}$ near the surface. This could be because many simplifications have been made in the derivation of $\theta_{e 2}$, while the value of $\theta_{e 1}$ is close to the real $\theta_{e}$. 

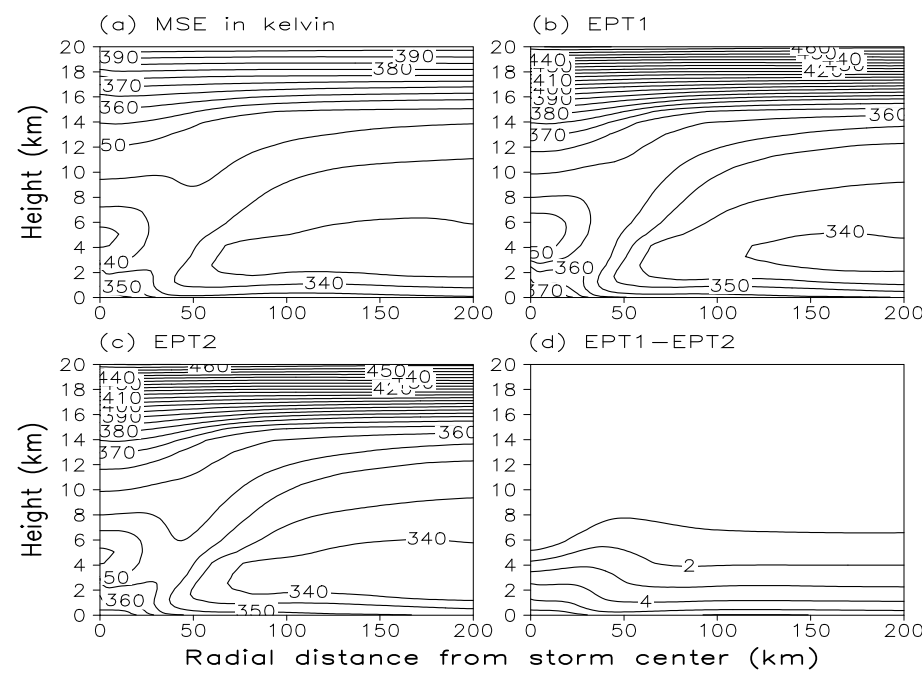

(d) EPT1-EPT2

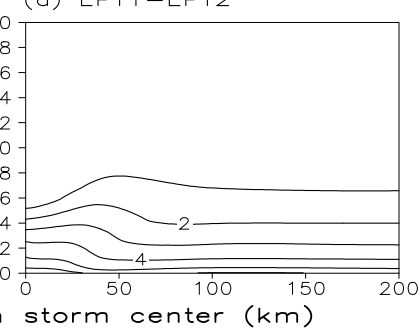

Figure 3. As in Figure 2, but for (a) MSE normalized by cp (K), (b) equivalent potential temperature (K) defined by Bolton (1980), (c) equivalent potential temperature (K) defined by Rotunno and Emanuel (1987), and (d) equivalent potential temperature difference (K) between definitions of Bolton (1980) and Rotunno and Emanuel (1987). The panels (a,b) incorporate the information in Figure 2 of Ma et al. (2015) [26], but are vertically extended to $20 \mathrm{~km}$ since an integration from model bottom to model top $(20 \mathrm{~km})$ is used in the following budget analysis.

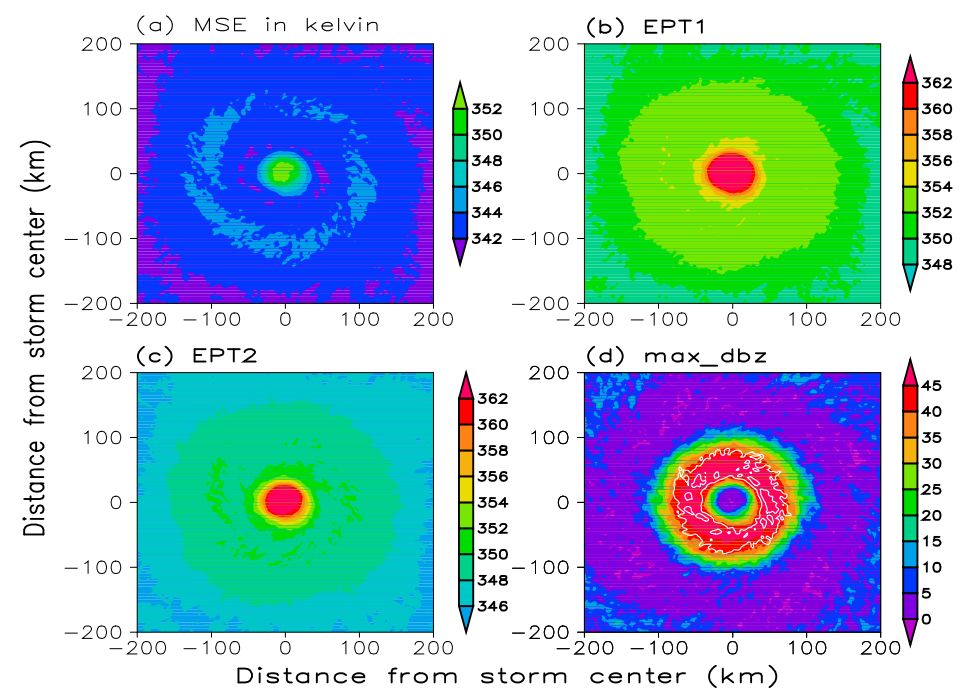

Figure 4. Plan views of temporally averaged boundary-layer (a) MSE normalized by $c_{p}(\mathrm{~K}),(\mathbf{b})$ equivalent potential temperature (K) defined by Bolton [35], (c) equivalent potential temperature (K) defined by Rotunno and Emanuel [36], and (d) temporal mean simulated maximum radar reflectivity (dBZ) between $108 \mathrm{~h}$ and $120 \mathrm{~h}$. Vertical averaging for $(\mathbf{a}-\mathbf{c})$ is taken over the lowest $1 \mathrm{~km}$. The cold pool of MSE with values smaller than $343 \mathrm{~K}$ is also superimposed on (d) by white lines at intervals of $1 \mathrm{~K}$.

Figure 4 displays plan views of the boundary-layer MSE, $\theta_{e 1}, \theta_{e 2}$, and simulated maximum radar reflectivity. For simplicity, a height of $1 \mathrm{~km}$ is taken as near the top of the boundary layer [38]. As shown in Figure 3, there is a maximum in the storm center for MSE, $\theta_{e 1}$, and $\theta_{e 2}$. Again, the MSE values are noticeably lower than those of $\theta_{e 1}$ and $\theta_{e 2}$. A prominent feature in Figure $4 \mathrm{a}$ is that the maximum MSE in the storm center is surrounded by a ring of low values immediately outside the eyewall. As a contrast, $\theta_{e}$ in Figure $4 \mathrm{~b}$ a,c monotonically decreases outward from the storm center, indicating that the calculated $\theta_{e}$ cannot fully capture the details of MSE in the boundary layer. This may lead to misinterpretation of the boundary-layer energy exchange between the inner-core and outer-core regions when MSE is assumed to be equivalent to $\theta_{e}$. The cold pool of MSE basically 
overlaps with the strongest radar reflectivity region (Figure 4d). It is thereby speculated that low MSE values are associated with precipitation-induced cooling. Such low-MSE air, if it invades into the eyewall before recovery, could undermine the energy cycle, which will inevitably result in decreased storm intensity [18]. In the interchangeable approximation between MSE and $\theta_{e}$, the rate of change in temperature following air motion is underestimated (see Appendix A). As such, $\theta_{e}$ cannot sufficiently incorporate such behavior of MSE, revealing that the substitution of $\theta_{e}$ by MSE could be problematic.

MSE in the eye region increases steadily as the storm intensifies (Figure 5a). There are mainly two mechanisms responsible for the increased MSE. One is enhancement of MSE from the upper troposphere, which is probably associated with warming of the troposphere caused by energy conversion in TCs [1-3]. The second is upward propagation from the ocean surface, which should arise from continuous upward transfer of heat fluxes. Figure 5 shows the respective contributions of IE, $\mathrm{PE}$, and LE to the whole MSE. IE is most pronounced at low levels, accounting for about $90 \%$ of MSE (Figure 5b). The ratio decreases with height to about 0.5, corresponding to the steady increase in the vertical of PE (Figure 5b). As expected, because water vapor in the troposphere decreases sharply with height, the contributions of LE are discernable only at low levels, with ratios lower than 0.15. Overall, the respective contributions of the component changes vary slightly with the storm development. The evolution of their specific contributions was further investigated at the upper and lower levels (Figure 6). In the upper troposphere, the relative importance of IE increases as the storm strengthens (Figure 6a), concurring with the evolutionary trend of MSE. Consequently, the other two components, PE and LE, contribute less or have no discernable change (not shown). In the boundary layer, LE contributes positively to increased MSE (Figure 6b), whereas changes in the contributions of the other two terms are negligible (not shown). This indicates that IE is dominant in enhancing MSE in the upper troposphere, and LE is dominant in the boundary layer. The behavior of MSE and each component was also investigated in other regions, including the eyewall (around the radius of maximum wind speed) and outer-core regions. Results are overall consistent with those in the eye region (not shown), implying that the above conclusion is suitable for the whole TC region.

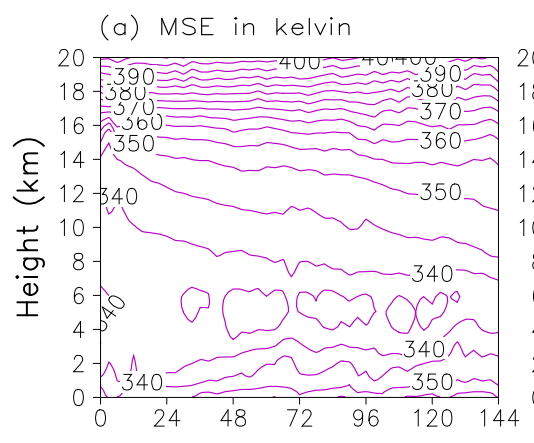

(b) IE/MSE

(c) PE/MSE
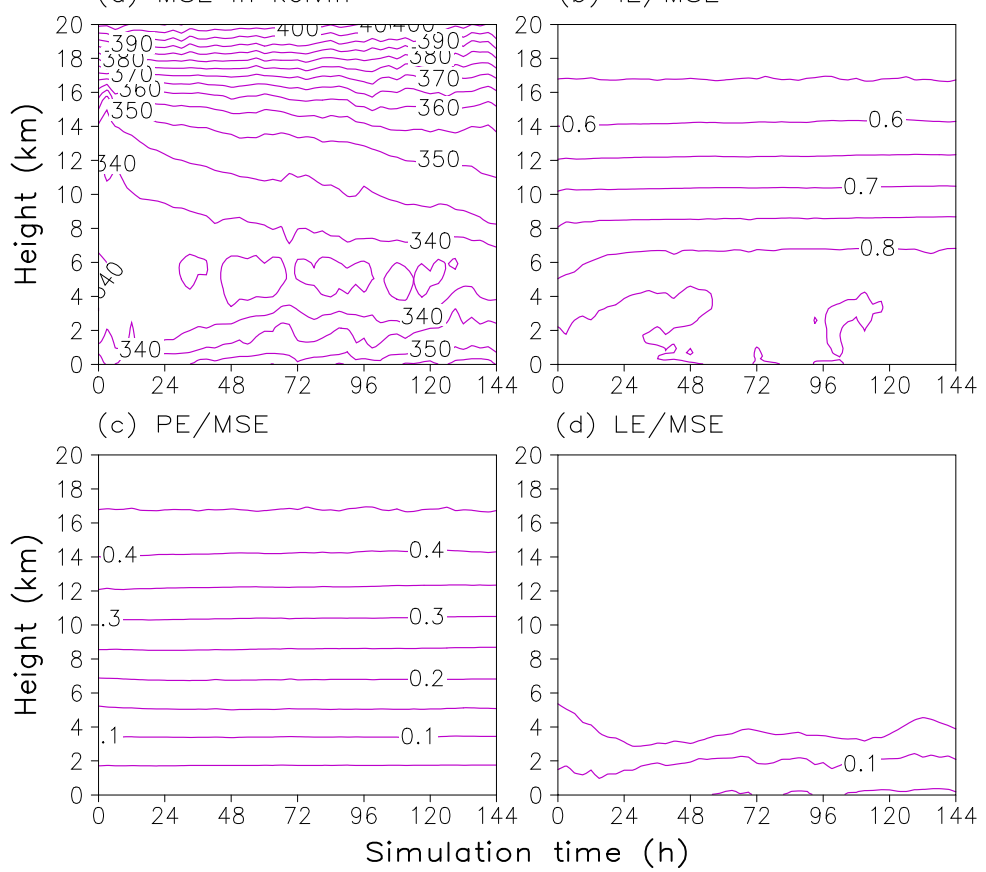

(d) LE/MSE

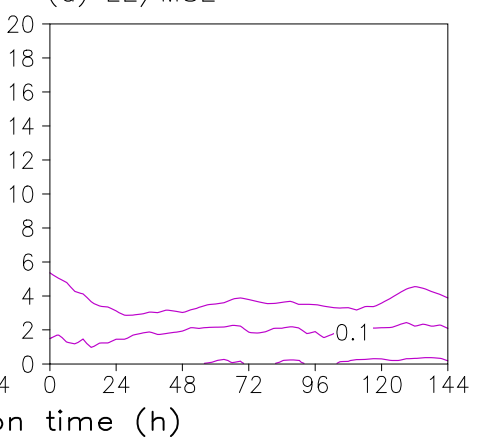

Figure 5. Time series of azimuthal and radial mean (a) MSE normalized by $c_{p}(\mathrm{~K})$ at contours of $5 \mathrm{~K}$, (b) ratio of internal energy (IE) to MSE at contours of 0.05, (c) ratio of potential energy (PE) to MSE at contours of 0.05 , and (d) ratio of latent energy (LE) to MSE in the storm eye at contours of 0.05 . Radial average is taken within a radius of $10 \mathrm{~km}$ from the storm center. 
(a) Ratio of IE/MSE in upper troposphere

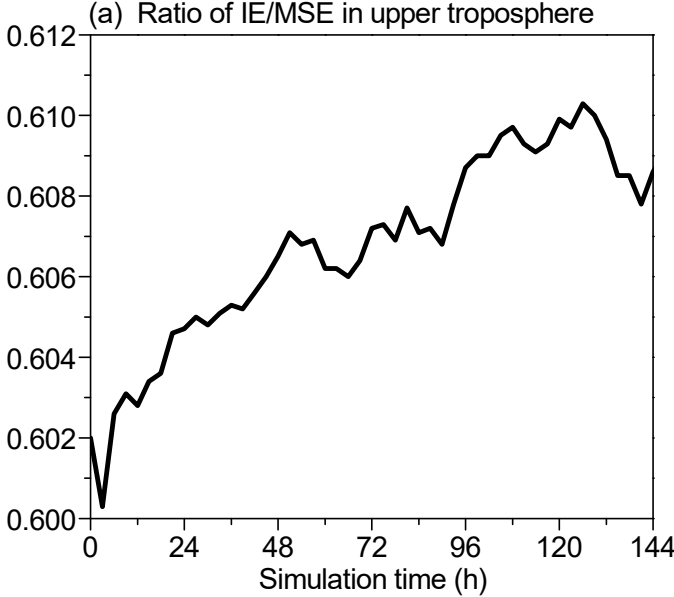

(b) Ratio of LE/MSE in boundary layer

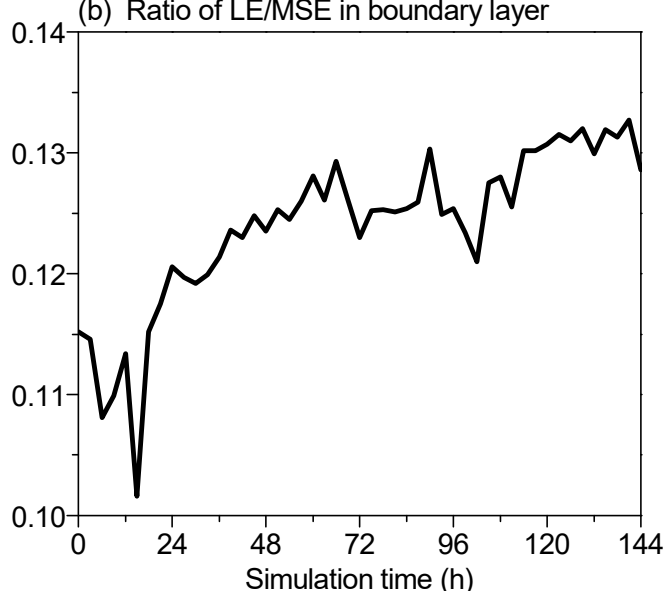

Figure 6. Time evolution of azimuthal and radial mean ratio of (a) IE to MSE in the upper troposphere (height of approximately $14 \mathrm{~km}$ ), and (b) LE to MSE in the boundary layer (height of approximately $1 \mathrm{~km})$.

\section{Column MSE Budget}

While the vertical integral of the $\theta_{e}$ budget in TCs has been evaluated in previous studies [36], the analysis above indicates that it may fully represent the behavior of MSE. Hence Equations (3), (5), and (6) are employed in this section to investigate the MSE budget over the whole atmosphere layer, the boundary inflow layer, and the upper outflow layer, respectively. An average time period of 108-120 h was examined while the simulated storm remained steady. Figure 7 shows composite radial distributions of all terms in the boundary-layer MSE budget. As expected, the local tendency of MSE is negligible relative to other terms since the storm intensity evolves slowly during this time period (Figure 1). HADV is most significant inside a radius of $50 \mathrm{~km}$, that is, in the eyewall region, where the rate of radial change in MSE is large and the radial inflow is intense (Figures $2 \mathrm{c}$ and $3 \mathrm{a}$ ). Of interest is that in the region where the radius ranges from approximately 50 to $100 \mathrm{~km}$, HADV is uniformly negative with values reaching $-1000 \mathrm{~W} \mathrm{~m}^{-2}$, indicating that the high MSE values following boundary-layer air parcels will be undermined before entering the eyewall under horizontal advection of radial inflow. From a radius of $100 \mathrm{~km}$ outward, HADV returns to positive values, but much smaller than in the inner core, indicating that MSE of inflow air increases slowly inward. As the upward motion in TCs is only active where the convection is present, VADV is analogously small in the periphery of the storm but remarkable in the inner core. It contributes negatively to the energy budget in the boundary layer, with peak values exceeding $-2000 \mathrm{~W} \mathrm{~m}^{-2}$, implying that MSE is removed from the boundary layer into the lower troposphere via ascending flow. EDDY is positive both inside and outside the eyewall, but is negative under the eyewall (approximately $25-40 \mathrm{~km}$ ). The former should be related to air mixing and exchange between the eye and the eyewall, while the latter is associated with downward entrainment of air at the boundary layer top [39]. Under the effects of these four processes, the net MSE changes are positive inside the eyewall and in the periphery but negative immediately outside the eyewall, approximately within a radius of $40-100 \mathrm{~km}$. This suggests that in some regions of the TC, the boundary-layer MSE does not increase uniformly before the storm decays, which is apparently different from the $\theta_{e}$ behavior. 
(a) Each Ihs term $\left(W / \mathrm{m}^{2}\right)$

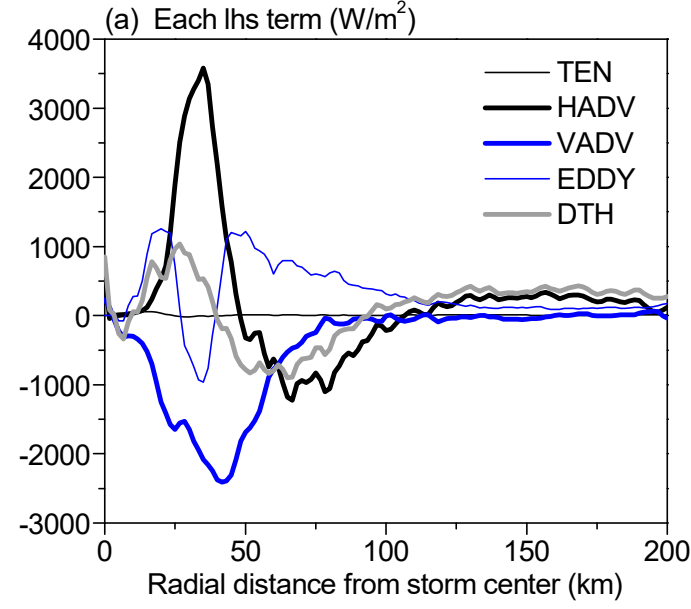

(b) Each rhs term $\left(\mathrm{W} / \mathrm{m}^{2}\right)$

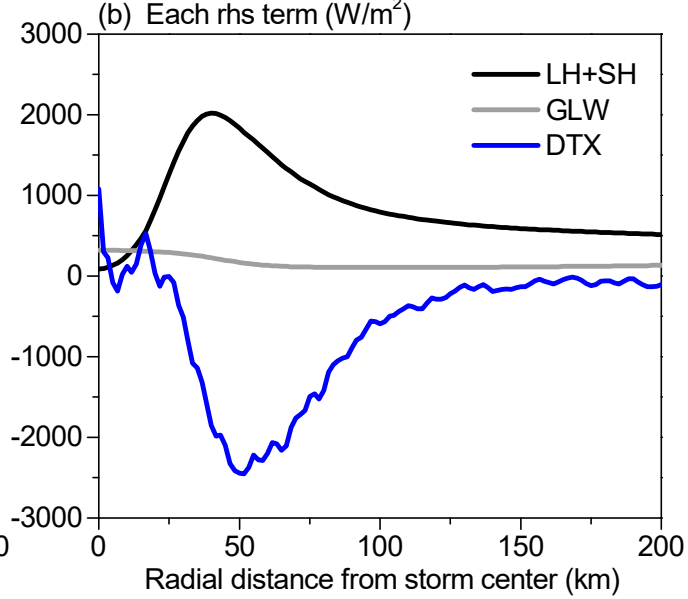

Figure 7. Radial distributions of (a) lhs and (b) rhs terms comprising boundary-layer MSE budget averaged between 108 and $120 \mathrm{~h}$. Vertical integral is taken from the surface to $1 \mathrm{~km}$ altitude.

The surface heat fluxes are significant in the eyewall region where the surface winds are the strongest (Figure $7 \mathrm{~b}$ ). The surface heat fluxes are shown to be the dominant energy source, evidencing one of the two mechanisms enhancing MSE (Figure 5a). Comparatively, the downward long-wave radiation fluxes at the ground surface can be neglected, though in the eye region these are slightly larger due to the absence of deep clouds. The fluxes at the boundary-layer top are computed as a residual of Equation (5). The computational bias will be discussed later. As seen in Figure 7b, a considerable part of MSE extracted from the ocean has been transported from the boundary layer into the troposphere to fuel the TC engine. The peak values of upward propagation occur outside the eyewall, similar to the $\theta_{e}$ budget in Ma et al. [12]. Of interest is that the upward fluxes at the top of the boundary layer overtake the surface fluxes in the cold pool of MSE, which could lead to a decreased boundary-layer MSE in that region, as shown in Figure 7a.

The budget of MSE in the upper troposphere is shown in Figure 8. The budget is integrated over a depth of about $10 \mathrm{~km}$ (from $10 \mathrm{~km}$ to the top of the model domain), but the peak values of the terms are smaller than those in the boundary layer owing to slower three-dimensional winds in the upper troposphere. Another common feature is the outward shift of peak values, which is caused by the outward tilt of the eyewall (Figure 2c). HADV is negative over the whole region, thereby advecting the high MSE outward from the TC to the surrounding environment. The resolved asymmetric eddies also contribute negatively to the MSE in the outflow layer. Nonetheless, VADV produces prominently positive values, signifying the warming effects of the upper troposphere due to the upward motion, which balances the discharge of MSE by HADV and EDDY. Unlike in the boundary layer, the net MSE change shows a roughly uniform increase, though the storm intensity is steady at this time period (Figure 1). The steady state condition of a TC was recently investigated by Smith et al. [38]. The long-wave radiation fluxes at the top of the atmosphere are small, as expected (Figure 8b), but have relatively large values in the eye region since deep clouds are nearly absent there. DBX is also calculated as a residual of Equation (6). The high MSE in the upper troposphere is found to be related to upward energy transport at the bottom surface, despite being distinctly smaller than that at the sea surface. In the outer region, DBX is much smaller compared to the radiation fluxes. 

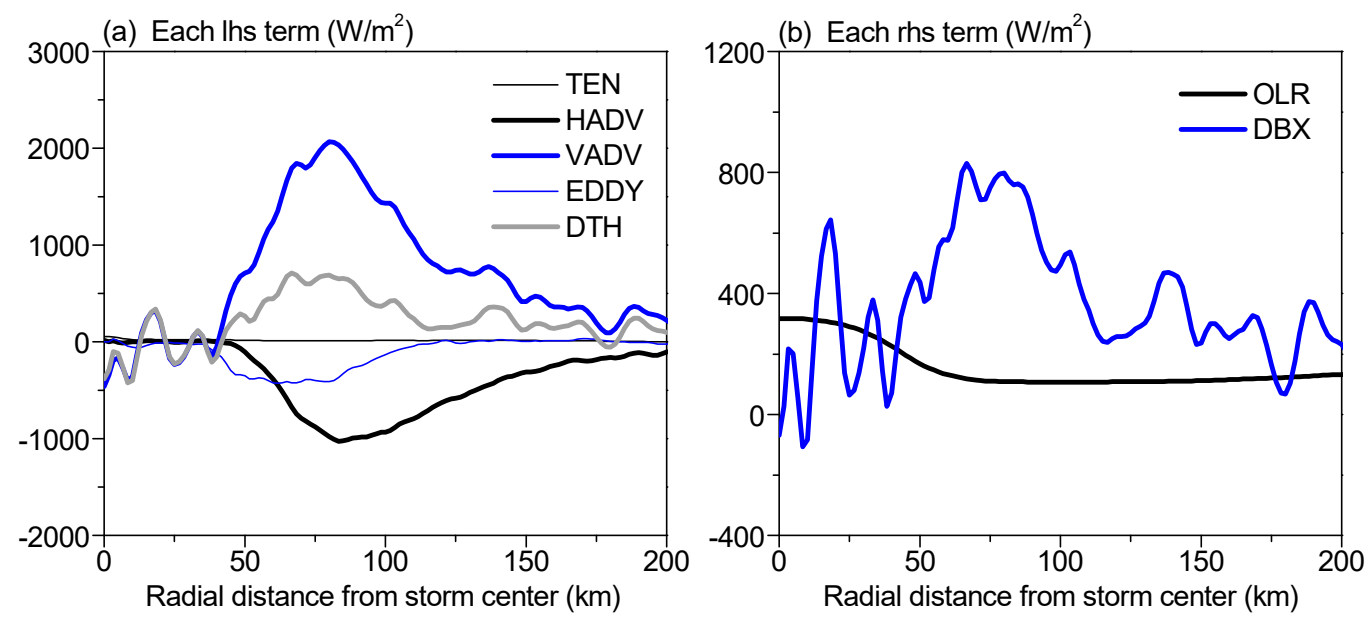

Figure 8. As in Figure 7, but for the upper-troposphere MSE budget for (a) lhs and (b) rhs terms. Vertical integral is taken from $10 \mathrm{~km}$ to the top of the model atmosphere.

Figure 9 shows the vertical integral of the MSE budget over the whole atmosphere. The contributions of HADV to the column MSE are overall negative, indicating that the role of radial outflow in the upper troposphere overall overwhelms that of the radial inflow in the low level. This is presumably because the radial outflow layer is relatively deep in the TC region. The radial distributions of VADV and EDDY resemble those in the upper troposphere, also identifying the more pronounced role of the upper troposphere than the boundary layer in changing the MSE over the whole atmosphere. From the behavior of DTH, there is both recharge and discharge of MSE in different TC regions. A volume budget is conducted in the next section for a quantitative examination.

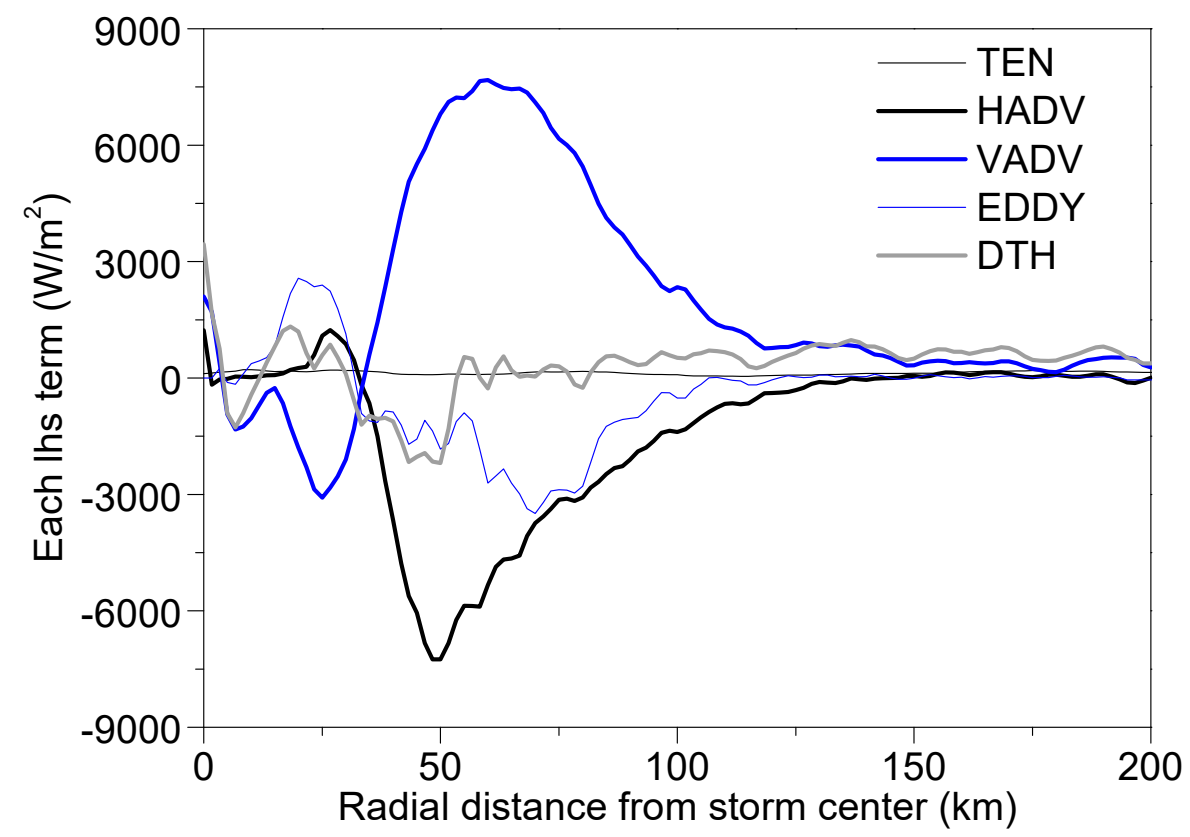

Figure 9. Radial distributions of lhs terms comprising whole-layer MSE budget averaged between 108 and $120 \mathrm{~h}$. Vertical integral is taken over the whole atmosphere layer.

\section{Volume MSE Budget}

The above column budget only demonstrates how MSE is transported inside the storm region by different processes. To quantify the energy exchange between the storm and the surrounding environment, a mass-weighted volume MSE budget is conducted in this section. For the sake of 
obtaining the volume-integrated form, a lateral-boundary-fixed control cylindrical volume centered at the storm center $(V)$ is first defined. The tendency of the volume-integrated, mass-weighted MSE to translate with the storm can be written as:

$$
\frac{d}{d t}\left(\int_{V} \rho h d V\right)=\left(\int_{V} \rho \frac{d h}{d t} d V\right)+\left(\int_{V} h \frac{d \rho}{d t} d V\right)
$$

Substituting Equation (3) into Equation (7) and employing the continuity equation, the conservation equation for volume MSE budget can be derived as:

$$
\frac{1}{S} \frac{d}{d t}\left(\int_{V} \rho h d V\right)=\frac{1}{S} \int_{S}(L H+S H) d S-\frac{1}{S} \int_{S}(G L W+O L R) d S+\left(-\frac{1}{S} \int_{V} \rho h \nabla \cdot \mathbf{V} d V\right),
$$

where $S$ is the boundary surface of the control volume and $\mathbf{V}$ is three-dimensional vector winds. From Equation (8), the change of mass-weighted MSE integrated over a volume relies on surface sensible and latent heat fluxes, radiation fluxes at the atmosphere bottom and top boundaries, and net fluxes of MSE across the lateral boundaries of the control volume. The lateral fluxes of MSE are obtained as the difference of the other three terms in Equation (8). Here the control cylindrical volume is defined with a height that extends from the surface up to the top of the model domain and a radius of $200 \mathrm{~km}$ from the storm center. A sensitivity test with a radius of $240 \mathrm{~km}$ gives similar results (not shown).

Looking first at the evolution of volume-averaged, mass-weighted MSE, shown in Figure 10, some interesting features are present. In spite of continuously small fluctuations around $1.583 \times 10^{5} \mathrm{~W} \mathrm{~m}^{-3}$ after the initial model spin-up, MSE does not vary by more than $0.5 \%$ throughout the simulation. As discussed above, the volume-averaged MSE itself does increase steadily as the storm strengthens (Figure 5a). Hence, the small change of volume-averaged, mass-weighted MSE is attributed to the offsetting roles of decreasing air density. As a storm strengthens, warming and expansion of the air in the upper troposphere and stratosphere should occur [40], accompanied by thinning of the atmosphere according to the gas law. Given that surface enthalpy fluxes should increase correlated to the storm strengthening, the mass-weighted MSE in a fixed volume is not consequently enhanced yet, which must result in more export or less input of MSE at the storm's lateral boundaries, or more outward radiation at top and bottom of the atmosphere, as indicated by Equation (8).

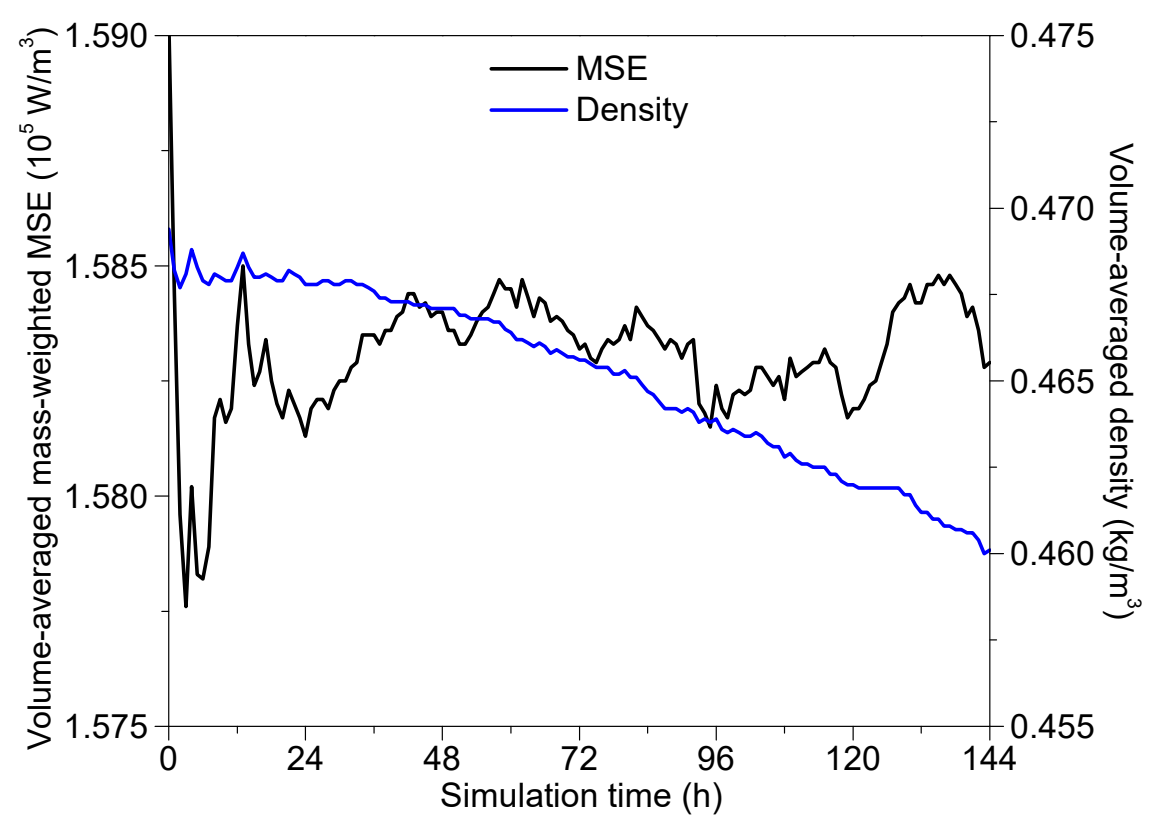

Figure 10. Time evolution of volume-averaged, mass-weighted MSE $\left(10^{5} \mathrm{~W} \mathrm{~m}^{-3}\right)$ and volume-averaged air density $\left(\mathrm{kg} \mathrm{m}^{-3}\right)$. 
The time evolution of all terms in the volume-averaged, mass-weighted MSE budget is displayed in Figure 11. To reduce noise with small time scales, the data were plotted every $3 \mathrm{~h}$. The tendency of mass-weighted MSE changes little during the storm's lifetime and produces near-zero values with small variation. The surface heat fluxes increase progressively until about $96 \mathrm{~h}$, when the storm intensifies to a mature state, and thereafter show small temporal variation. The sum of long-wave radiation fluxes at the top and bottom of the atmosphere are nearly invariant throughout the simulation, indicating that the radiation is hardly affected by the storm intensity variation. The difference between radiation fluxes and surface heat fluxes is enlarged as the storm intensifies. Of interest is that the radiation fluxes are comparable to surface heat fluxes. This is because a cylindrical volume with a radius of $200 \mathrm{~km}$ is taken for the budget calculation in order to fully contain the TC regime, while in the periphery of the storm the surface enthalpy fluxes are not as large as in the inner core region due to rapidly diminished surface winds outward (Figures $7 \mathrm{~b}$ and $8 \mathrm{~b}$ ). The fluxes of MSE at lateral boundaries are roughly negative after an initially rapid adjustment, suggesting that the TC exports MSE throughout its lifetime, as also found by McBride [41] from composites of rawinsonde data. The absolute values of lateral fluxes give a promisingly proportional relationship with storm intensity in that they are steadily enlarged as the storm strengthens until approximately $96 \mathrm{~h}$, and thereafter are roughly around a certain threshold with fluctuations present. This indicates that the lateral export of MSE closely depends on the storm intensity. For a specified storm, the more intensified it is, the more export of MSE there tends to be. Another distinctive feature is that the fluxes of MSE by lateral export are smaller in magnitude than those by radiation, despite the radiation fluxes being negligibly small relative to other terms in the column MSE budget (Figures 7-9). This can be attributed to the offsetting effects among other terms at different heights. For instance, the radial outflow in the upper levels spreads large amounts of MSE outward, far exceeding the loss by radiation, which nonetheless is largely offset by the input of MSE associated with the low-level inflow air. We conducted an additional budget analysis with the radius set at $100 \mathrm{~km}$, in which the lateral fluxes give larger values than, but still comparative to, the radiation fluxes (not shown).

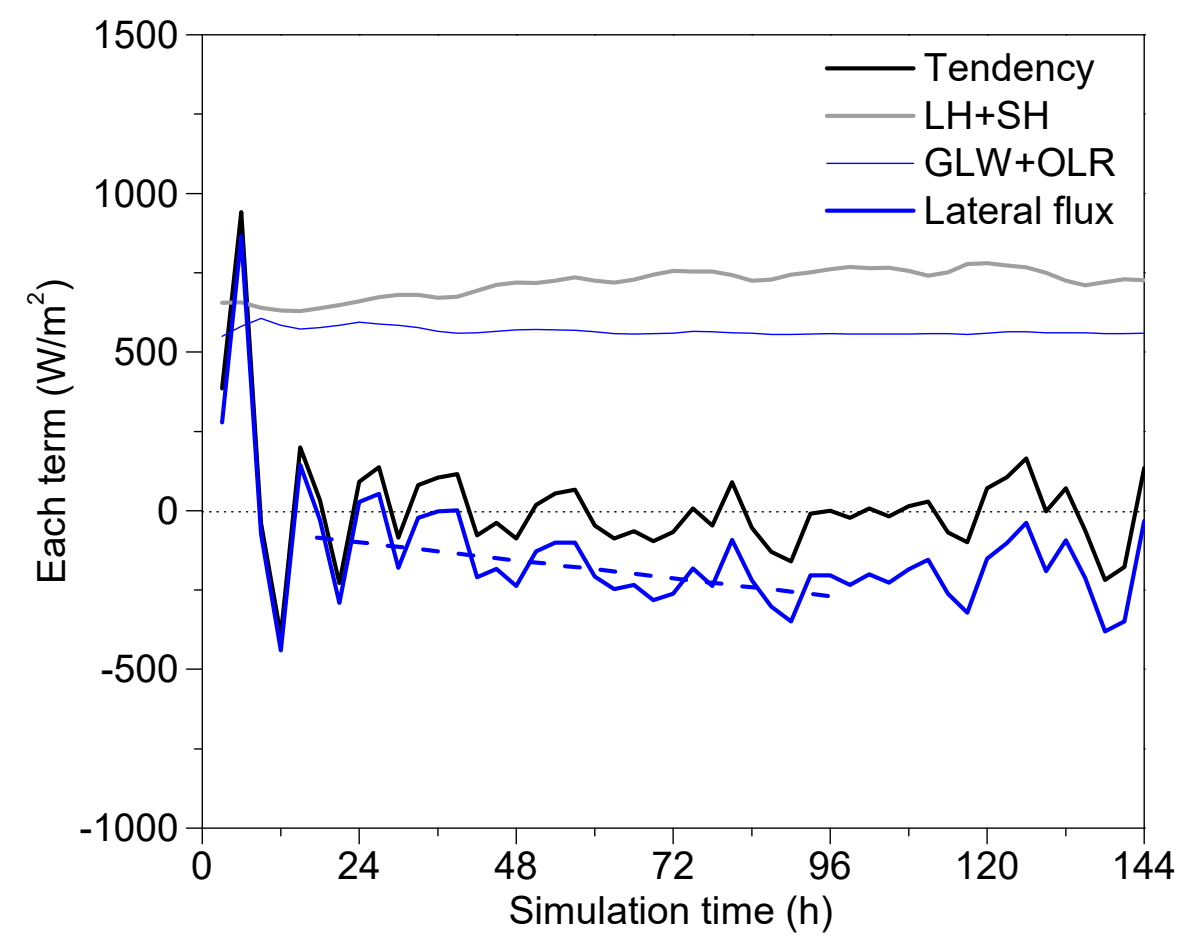

Figure 11. Time evolution of all terms comprising volume-integrated, mass-weighted MSE budget.

Figure 12 illustrates the conceptual schematic of the input and export of MSE in the TC system. The budget values are averaged after $24 \mathrm{~h}$ of simulation from the mass-weighted volume MSE budget, 
and then normalized by adjusting the contributions of surface enthalpy fluxes to 100 . Since the input of MSE by low-level inflow has been offset by the export of MSE associated with the upper-level outflow, the surface enthalpy fluxes turn out to be the only source enhancing MSE in the TC system. A great majority of the imported MSE ( $77.1 \%$ in this study) is consumed by upward radiation at the top of the atmosphere and downward radiation at the surface. Only a small portion of the imported MSE $(24.1 \%)$ is propagated into the surrounding environment by the radial outflow as a residual after balancing the input of MSE by the low-level inflow. Due to radiation and warming-induced expansion of the upper-level air, the mass-weighted MSE in a TC system hardly retains the recharge from sea surface or boundary inflow (with a slight deficit of $-1.2 \%$ in this study), whether or not the storm is experiencing intensification or maintaining its mature state.

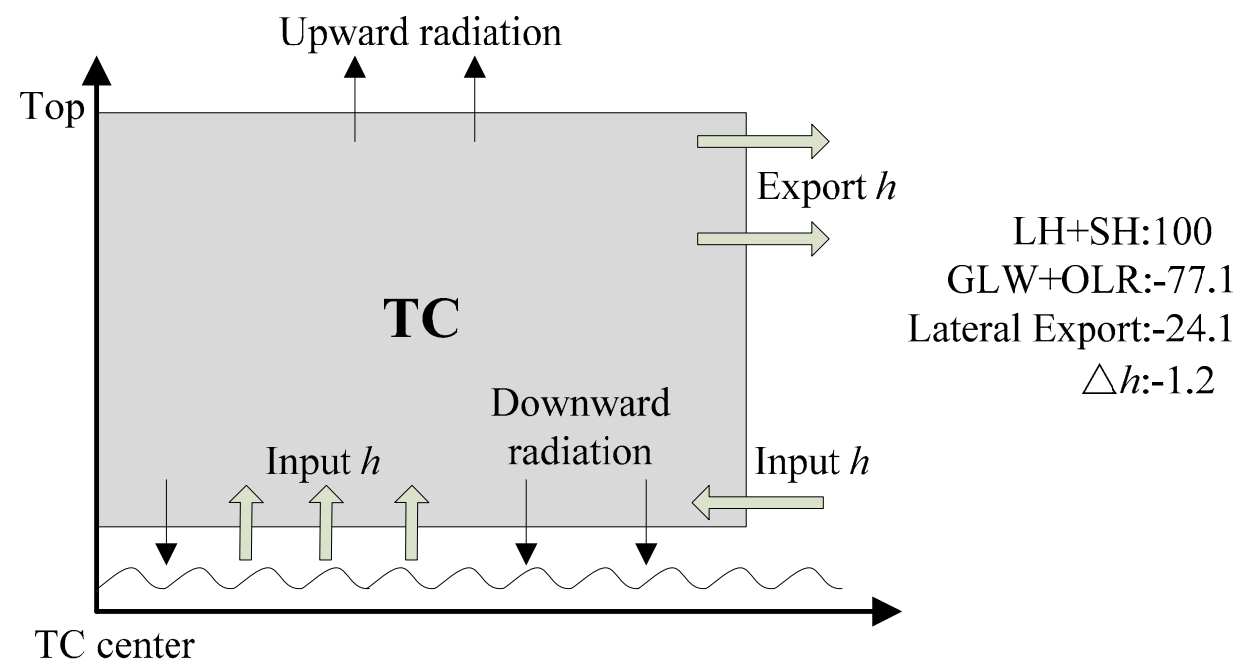

Figure 12. Schematic diagram of in and out of MSE over the tropical cyclone (TC) region. Values shown for terms are averaged after $24 \mathrm{~h}$ of integration from volume-integrated, mass-weighted MSE budget and normalized by adjusting the values of surface enthalpy fluxes to $100 \mathrm{~W} \mathrm{~m}^{-2}$.

\section{Summary}

Moist static energy (MSE) is a common quantity for studying the evolution of many convective systems since it incorporates different forms of energy explicitly. In this paper, the characteristics of moist static energy in TCs are investigated on the basis of a case simulation of an idealized tropical cyclone. Since $\theta_{e}$ is often used as an equivalence of moist static energy, a comparison of the structures of moist static energy and $\theta_{e}$ is also performed to inspect the validity of this interchangeable approximation. Two conventionally used forms of $\theta_{e}$, introduced by Bolton [35] and Rotunno and Emanuel [36], are found to be capable of capturing the overall structure of moist static energy. However, some important features are still distorted by moist static energy. In the boundary layer, the core of high moist static energy in the TC center is surrounded by a pool of low moist static energy, which is hardly detected by both forms of $\theta_{e}$. Such MSE-based dry and cool air may not be sufficiently recovered before entering the eyewall updraft, thus potentially inhibiting the TC heat engine. Besides, large differences exist in the spatial gradients of moist static energy and the two forms of $\theta_{e}$. Caution should be used when equating $\theta_{e}$ with moist static energy. Moist static energy is steadily enhanced as the storm strengthens. Two mechanisms are indicated to be responsible for the increased moist static energy. One is upward propagation from the sea surface, specifically the increase of LE via surface latent heat fluxes, though its contributions are only discernable at low levels. The other is warming of the upper troposphere with storm intensification, that is, increased internal energy in the upper levels.

The vertical integral of the MSE budget in the boundary layer shows that surface enthalpy fluxes are the dominant factor enhancing the MSE of the boundary layer. The horizontal advection also mostly contributes positively to the boundary layer MSE, but it plays a negative role in the low-MSE 
ring region, where the MSE of inflow air is diminished by precipitation-induced cooling. Overall, a considerable part of MSE extracted from the ocean is transported from the boundary layer into the troposphere, and the discharge of MSE could overwhelm its recharge in the low-MSE pool. The most significant energy exchange between the boundary layer and the troposphere aloft occurs outside the eyewall rather than right below it. The vertical integral of the MSE budget in the upper troposphere indicates that vertical advection brings in large amounts of MSE, which are mostly exported into the environment by horizontal advection. The role of radiation fluxes at the top and bottom of the atmosphere is far smaller than that of surface enthalpy fluxes near the eyewall region, but it cannot be neglected in the eye and outer storm periphery regions, where the storm winds are weak.

Unlike the volume-averaged MSE, the mass-weighted MSE in a fixed volume does not apparently increase throughout the lifetime of the simulated storm. This is because the air becomes thinner as the troposphere is steadily warmed accompanying the storm intensification. A mass-weighted volume MSE budget is further analyzed to quantify the energy exchange between the TC system and the surrounding environment. From the equation, the quantities of mass-weighted MSE in a fixed volume rely on surface enthalpy fluxes, radiation effects, and input or export of MSE at the lateral boundaries. The radiation effects are shown to depend very weakly on variation in storm intensity. The simulated TC system is found to export MSE whether or not it is undergoing intensification or maturity. It is simultaneously found that for a specified storm, the export of MSE closely relies on the storm intensity, in that the more intensified it is, the more export of MSE there tends to be. Since the input of MSE by low-level inflow is offset by the export of MSE associated with the upper-level outflow, the surface enthalpy fluxes turn to be the only source enhancing the MSE in the TC system. A great majority of the imported MSE by surface enthalpy fluxes is consumed by upward radiation at the top of the atmosphere and downward radiation at the surface, while only a small portion is transported into the surrounding environment. The input of MSE is roughly balanced by the export of MSE.

It should be mentioned that the simulated TC in this study evolved in a beneficial environment with quiescent flow and uniform sea surface temperature. Storms in the real environment should have more asymmetric MSE characteristics due to the presence of vertical wind shear, steering flow, uneven sea surface temperature, etc., and thus further real case studies are warranted. Finally, it should be noted that this study is based on an idealized simulation and the results may be quantitatively different according to variations of model configurations, resolutions, sounding profiles, and a variety of other factors.

Author Contributions: L.Y. post-processed the model data and drew all the figures; S.W. organized the structure of the manuscript and contributed to the writing; this work is motivated by Z.M., who also provided the model data.

Funding: This research was funded by the National Natural Science Foundation of China with grant number 41875062.

Acknowledgments: We thank two anonymous reviewers for their comments to improve the manuscript.

Conflicts of Interest: The authors declare no conflicts of interest.

\section{Appendix A. Interchangeable Approximation between MSE and $\theta_{e}$}

Appendix A.1. Conservation of MSE

According to Equation (1), MSE change can be written as:

$$
d h=c_{p} d T+g d z+L_{v} d q .
$$

Recall the first law of thermodynamics:

$$
c_{p} d T-\frac{d p}{\rho}+L_{v} d q=d Q
$$


where $d Q$ denotes diabatic heating. Equating Equations (A1) and (A2) leads to the conservation property of MSE, which assumes $\frac{d p}{d z}=-\rho g$.

Applying the equation of full differential $\frac{d p}{d t}=\frac{\partial p}{\partial t}+\mathbf{V} \bullet \nabla p+w \frac{\partial p}{\partial z}$ and $\frac{d z}{d t}=w$, and assuming the atmosphere is in hydrostatic balance and the horizontal advection of pressure can be neglected, the relationship of $\frac{d p}{d z} \approx-\rho g$ can be derived. Ma et al. [38] noted that there are biases regarding the above assumptions that could cause problems with the conservation property of MSE in the boundary layer even if there is no interaction or mixing with the surrounding air.

Appendix A.2. Approximate Equivalence between MSE and $\theta_{e}$

The interchangeable relationship between MSE and $\theta_{e}$ was discussed by Riehl [42]. It is reintroduced below for completeness. By dividing Equation (A2) by $c_{p} T$, the first law of thermodynamics can be rearranged as:

$$
\frac{d T}{T}-\frac{R d p}{c_{p} p}+\frac{L_{v} d q}{c_{p} T}=\frac{d Q}{c_{p} T}
$$

Note that the gas law was applied in deriving (A4). The sum of two lhs terms in Equation (A4) is equivalent to $d \ln \theta$. For air motion where the rate of change in $q$ is much larger than that in $T$, Equation (A4) is changed to:

$$
d \ln \theta+d\left(\frac{L_{v} q}{c_{p} T}\right)=\frac{d Q}{c_{p} T}
$$

Given that [36]:

$$
\theta_{e} \approx \theta \exp \left(\frac{L_{v} q}{c_{p} T}\right)
$$

the interchangeable relationship between MSE and $\theta_{e}$ can be obtained as:

$$
c_{p} T d \ln \theta_{e} \approx d h=d Q .
$$

There are some simplifications to reach the interchangeable relationship, including assuming hydrostatic balance and a much larger rate of change in $q$ than in $T$, and neglecting the horizontal advection of pressure. Although this approximation is shown to be accurate at least in the upper troposphere of the tropics [42], it has limitations in that the rate of change in $T$ was omitted in deriving Equation (4), which may make the replacement between the two terms problematic.

\section{References}

1. Tuleya, R.E.; Kurihara, Y. The energy and angular momentum budgets of a three-dimensional tropical cyclone model. J. Atmos. Sci. 1975, 32, 287-301. [CrossRef]

2. Hogsett, W.; Zhang, D.-L. Numerical simulation of Hurricane Bonnie (1998). Part III: Energetics. J. Atmos. Sci. 2009, 66, 2678-2696. [CrossRef]

3. Malkus, J.S.; Riehl, H. On the dynamics and energy transformation in steady-state hurricanes. Tellus 1960, 12, 1-20. [CrossRef]

4. Emanuel, K. 2004: Tropical Cyclone Energetics and Structure. In Atmospheric Turbulence and Mesoscale Meteorology; Fedorovich, E., Rotunno, R., Stevens, B., Eds.; Cambridge University Press: Cambridge, UK; 280p.

5. Wong, V.; Emanuel, K. Use of cloud radars and radiometers for tropical cyclone intensity estimation. Geophys. Res. Lett. 2007, 34, L12811. [CrossRef]

6. Zhu, H.; Smith, R.K. The importance of three physical processes in a minimal three-dimensional tropical cyclone model. J. Atmos. Sci. 2002, 59, 1825-1840. [CrossRef]

7. Bender, M.A.; Ginis, I. Real-case simulation of hurricane-ocean interaction using a high-resolution coupled model: Effects on hurricane intensity. Mon. Weather Rev. 2000, 128, 917-946. [CrossRef]

8. Hong, X.; Chang, S.W.; Raman, S.; Shay, L.K.; Hodur, R. The interaction between Hurricane Opal (1995) and a warm core ring in the Gulf of Mexico. Mon. Weather Rev. 2000, 128, 1347-1365. [CrossRef] 
9. Zhu, H.; Wolfgang, U.; Smith, R.K. Ocean effects on tropical cyclone intensification and inner-core asymmetries. J. Atmos. Sci. 2004, 61, 1245-1258. [CrossRef]

10. Fierro, A.O.; Simpson, J.; LeMone, M.A.; Straka, J.M.; Smull, B.F. On how hot towers fuel the Hadley cell: An observational and modeling study of line-organized convection in the equatorial trough from TOGA COARE. J. Atmos. Sci. 2009, 66, 2730-2746. [CrossRef]

11. Fierro, A.O.; Zipser, E.J.; LeMone, M.A.; Straka, J.M.; Simpon, J. Tropical oceanic hot towers: Need they be undiluted to transport energy from the boundary layer to the upper troposphere effectively? An answer based on trajectory analysis of a simulation of a TOGA COARE convective system. J. Atmos. Sci. 2012, 69, 195-213. [CrossRef]

12. Ma, Z.; Fei, J.; Huang, X.; Cheng, X. The Effects of ocean feedback on tropical cyclone energetics under idealized air-sea interaction conditions. J. Geophys. Res. 2013, 118. [CrossRef]

13. Barnes, G.M.; Zipser, E.J.; Jorgensen, D.; Marks, F.D. Mesoscale and convective structure of a hurricane rainband. J. Atmos. Sci. 1983, 40, 2125-2137. [CrossRef]

14. Powell, M.D. Boundary layer structure and dynamics in outer hurricane rainbands. Part I: Mesoscale rainfall and kinematic structure. Mon. Weather Rev. 1990, 118, 891-917. [CrossRef]

15. Powell, M.D. Boundary layer structure and dynamics in outer hurricane rainbands. Part II: Downdraft modification and mixed layer recovery. Mon. Weather Rev. 1990, 118, 918-938. [CrossRef]

16. Hence, D.A.; Houze, R.A., Jr. Kinematic structure of convective-scale elements in the rainbands of Hurricanes Katrina and Rita (2005). J. Geophys. Res. 2008, 113, D15108. [CrossRef]

17. Didlake, A.C., Jr.; Houze, R.A., Jr. Convective-scale downdrafts in the principal rainband of Hurricane Katrina (2005). Mon. Weather Rev. 2009, 137, 3269-3293. [CrossRef]

18. Riemer, M.; Montgomery, M.T.; Nicholls, M.E. A new paradigm for intensity modification of tropical cyclones: Thermodynamic impact of vertical wind shear on the inflow layer. Atmos. Chem. Phys. 2010, 10, 3163-3188. [CrossRef]

19. Maloney, E.D. The moist static energy budget of a composite tropical intraseasonal oscillation in a climate model. J. Clim. 2009, 22, 711-729. [CrossRef]

20. Kuang, Z. The wavelength dependence of the gross moist stability and the scale selection in the instability of column integrated moist static energy. J. Atmos. Sci. 2011, 68, 61-74. [CrossRef]

21. Andersen, J.A.; Kuang, Z.M. Moist static energy budget of MJO-like disturbances in the atmosphere of a zonally symmetric aquaplanet. J. Clim. 2012, 25, 2782-2804. [CrossRef]

22. Cai, Q.; Zhang, G.J.; Zhou, T. Impacts of shallow convection on MJO simulation: A moist static energy and moisture budget analysis. J. Clim. 2013, 26, 2417-2431. [CrossRef]

23. Frank, W.M. The structure and energetics of the tropical cyclone II. Dynamics and energetics. Mon. Weather Rev. 1977, 105, 1136-1150. [CrossRef]

24. Yanai, M.S.; Esbensen, S.; Chu, J. Determination of bulk properties of tropical cloud clusters from large-scale heat and moisture budgets. J. Atmos. Sci. 1973, 30, 611-627. [CrossRef]

25. Chen, H.; Zhang, D.-L.; Carton, J.; Atlas, R. On the rapid intensification of Hurricane Wilma (2005). Part I: Model prediction and structural changes. Weather Forecast. 2011, 26, 885-901. [CrossRef]

26. Ma, Z.; Fei, J.; Huang, X.; Cheng, X. A potential problem of the applications of moist static energy in tropical cyclone studies. J. Atmos. Sci. 2015, 72, 3009-3019.

27. Skamarock, W.C.; Klemp, J.B.; Dudhia, J.; Gill, D.O.; Barker, D.M.; Wang, W.; Powers, J.G. A Description of the Advanced Research WRF Version 3; NCAR Tech. Note NCAR/TN-475+ST; NCAR: Boulder, CO, USA, 2008; p. 113.

28. Lin, Y.L.; Farley, R.D.; Orville, H.D. Bulk parameterization of the snow field in a cloud model. J. Appl. Meteorol. Climatol. 1983, 22, 1065-1092. [CrossRef]

29. Hong, S.Y.; Noh, Y.; Dudhia, J. A new vertical diffusion package with an explicit treatment of entrainment processes. Mon. Weather Rev. 2006, 134, 2318-2341. [CrossRef]

30. Dudhia, J. Numerical study of convection observed during the Winter Monsoon Experiment using a mesoscale two dimensional model. J. Atmos. Sci. 1989, 46, 3077-3107. [CrossRef]

31. Mlawer, E.J.; Taubman, S.J.; Brown, P.D.; Iacono, M.J.; Clough, S.A. Radiative transfer for inhomogeneous atmosphere: RRTM, a validated correlated-k model for the longwave. J. Geophys. Res. 1997, 102, 16663-16682. [CrossRef]

32. Jordan, C.L. Mean soundings for the West Indies area. J. Atmos. Sci. 1958, 15, 91-97. [CrossRef] 
33. Kepert, J.D.; Wang, Y. The dynamics of boundary layer jets within the tropical cyclone core. Part II: Nonlinear enhancement. J. Atmos. Sci. 2011, 58, 2485-2501. [CrossRef]

34. Zhang, D.-L.; Chen, H. Importance of the upper-level warm core in the rapid intensification of a tropical cyclone. Geophys. Res. Lett. 2012, 39, L02806. [CrossRef]

35. Bolton, D. The computation of equivalent potential temperature. Mon. Weather Rev. 1980, 108, $1046-1053$. [CrossRef]

36. Rotunno, R.; Emanuel, K. An air-sea interaction theory for tropical cyclones. Part II: Evolutionary study using a nonhydrostatic axisymmetric model. J. Atmos. Sci. 1987, 44, 542-561. [CrossRef]

37. Darkow, G.L. Basic thunderstorm energetics and thermodynamics. In Thunderstorm Morphology and Dynamics; Kessler, E., Ed.; University of Oklahoma Press: Norman, OK, USA, 1986; pp. 59-73.

38. Smith, R.K.; Montgomery, M.T.; Persing, J. On steady-state tropical cyclones. Q. J. R. Meteorol. Soc. 2014, 140, 2638-2649. [CrossRef]

39. Wroe, D.R.; Barnes, G.M. Inflow layer energetics of Hurricane Bonnie (1998) near landfall. Mon. Weather Rev. 2003, 131, 1600-1612. [CrossRef]

40. Chen, H.; Zhang, D.-L. On the rapid intensification of Hurricane Wilma (2005). Part II: Convective bursts and upper-level warm core. J. Atmos. Sci. 2013, 70, 146-162. [CrossRef]

41. McBride, J.L. Observational analysis of tropical cyclone formation. Part III: Budget analysis. J. Atmos. Sci. 1981, 38, 1152-1166. [CrossRef]

42. Riehl, H. Climate and Weather in the Tropics; Academic Press: Cambridge, MA, USA, 1979; p. 611.

(C) 2019 by the authors. Licensee MDPI, Basel, Switzerland. This article is an open access article distributed under the terms and conditions of the Creative Commons Attribution (CC BY) license (http://creativecommons.org/licenses/by/4.0/). 